The BMJ

Cite this as: BMJ 2021;373:n1209 http://dx.doi.org/10.1136/bmi.n1209 Published: 17 May 2021

\section{How can I refocus on my career after the pandemic?}

Working through an extremely difficult period has left some doctors with an opportunity to assess
their career options. Abi Rimmer hears what next steps might be useful at this stage Abi Rimmer

\section{Think back to why you went into medicine}

Adam Harrison, doctor and career and leadership coach for doctors, says, "Reflect on what you want for your post-pandemic life. Really think about what your life as a whole is currently like and consider the impact your work is having on your non-working life. If anything was possible, how would your career ideally look in five years?

"What values guide you? If you can't put them into words, complete this survey: www.viacharacter.org/survey/account/register. Think about how your career progression would best align with those values. If you embark on a pathway that isn't in alignment with your core values, it will likely be unfulfilling and may lead to unhappiness, but if you do the opposite, you're more likely to thrive.

"Think about your interests and skills. The pandemic has created a shift in how medicine is practised and this is a good time to consider whether it works for you. If it doesn't, this might be an opportunity to pivot into an area that interests you.

"Similarly, if you feel you're not currently using all the skills in your toolkit, there might be a different area within-or even a profession outside of-medicine where you could start making use of them again. Don't forget the myriad transferable skills you have as a medic.

"Finally, think back to your original reasons for going into medicine. It's always worth going back and remembering what it was that made you apply to medical school in the first place. Do those attractions still exist for you? If not, think about why and if you need to do something about that."

\section{Work out what makes a good day for you}

Claire Kaye, executive coach specialising in career development and former portfolio GP, says, "It's been an incredibly difficult year. Thankfully, we're starting to see some light at the end of the tunnel and with that comes the chance to think about the future. When was the last time you stopped, took a moment, and asked yourself what you want?

"It's likely that a lot has changed in your day-to-day work during the pandemic. With change comes challenges but also plenty of opportunities. Acknowledging these is a useful starting point in learning more about yourself.

“The next step is to reflect on how you're feeling right now. Do you love your job, are you too exhausted to care, or are you somewhere in between? Understanding this allows you to identify some of the factors that motivate and demotivate you. time you had a great day at work was. Why was it such a great day and how did you feel? Then ask yourself the same questions about the last time you had a challenging day. Aim to decrease or stop doing what demotivates you and embrace more of what interests you.

"It's also important to look at how you respond to difficult situations. Do you get stressed and overwhelmed or do you take a step back and think about how you could tackle things differently. Being proactive and taking responsibility for how you respond to challenges in your career can help to reshape your mindset.

"Understanding your motivators, demotivators, and mindset will empower you to start to plan and reshape your future. For most people, making these few tweaks will be enough to reignite the love of your career.”

\section{Take the time to reflect and take stock}

Katya Miles, founder of Working Well Doctor and head of training at Joyful Doctor, says, "Start with giving yourself permission to get well-you make much better career decisions from a place of wellness. Get help if you need it. Many of us with caring roles struggle to give ourselves this permission, but it's crucial. Without it, you can't access all the other career development tools.

"Next, give yourself permission to carve out, not just the time, but the headspace needed to reflect. You may like to try exercise, getting creative, journaling, or joining a wellbeing workshop.

“Then take stock. A lot has happened. Your career goals may have changed. Your personal circumstances or priorities may have shifted. What is important to you now? Many of us have upskilled to meet the demands of the pandemic, so you may like to do a skills inventory. You may have become better at leading, dealing with uncertainty, or supporting colleagues. All these are valuable skills for many careers.

"So many of us have experienced huge stressors. It helps to ask yourself what your stress triggers are, and what career path would minimise these. Do your research, speak to others, and ask yourself what you want to be doing in 10 years' time. Think broadly and include non-traditional career paths too. And don't forget the positives-what brings you joy either in or out of work, and how can you weave this into your future career?

"And, finally, think about your personality-what would be a good fit for you? Talking to a career coach
"Try this simple exercise: ask yourself when the last 
can be a great help. You only have this one 'wild and precious life,' so it's worth taking the time to make your career work for you." 